\title{
STEROL AND TRITERPENOIDS FROM HYGROPHILA SCHULLI BUCH.-HAM.
}

\author{
Md Abu Sufian, Fatema Begum, Mohammad Rashedul Haque, Choudhury \\ Mahmood Hasan and Mohammad Abdur Rashid*
}

Department of Pharmaceutical Chemistry, University of Dhaka, Dhaka-1000, Bangladesh

Key words: Hygrophila schulli, Stigmasterol, Lupeol, lup-20(29)-ene-3ß, 23-diol

\begin{abstract}
The methanol extract of whole plants of Hygrophila schulli Buch.-Ham. was subjected to repeated chromatographic separation and purification processes to isolate its chemical constituents. A total of three compounds were isolated which have been characterized as stigmasterol, lupeol and lup-20(29)-ene-3 $\beta, 23-$ diol on the basis of ${ }^{1} \mathrm{H}$ NMR spectral evidence and confirmed by comparing with published data, as well as co-TLC in case of stigmasterol and lupeol. This is the first report of lup-20(29)-ene-3 $\beta, 23$-diol from this plant.
\end{abstract}

Hygrophila schulli Buch.-Ham. (Fam.: Acanthaceae) is an annual erect, unbranched herb which is widely distributed throughout Bangladesh. Its common habitats are moist places, on banks of ponds, ditches and paddy fields. Due to its wide availability and enormous medicinal values, ethnic people of Bangladesh have been using this plant from the time unknown. The ethnic people of Patuakhali district of Bangladesh use fresh aerial parts of the plant and ash in dropsy. The Garo tribe living in Mymensingh district of Bangladesh uses the plant in diarrhea, dysentery, and cough. The roots and leaves are diuretic and used in the treatment of dropsy, jaundice and urinogenital diseases. Seed juice is useful to mother during child birth. On the other hand the leaf paste is applied externally to lumbago and rheumatism (Ahmed et al. 2007 - 2009).

As a part of our ongoing research on medicinal plants of Bangladesh (Haque et al. 2005, Ara et al. 2012, Sikder et al. 2013, Begum et al. 2014), H. schulli was studied and herein, a sterol and two triterpenoids are reported.

NMR spectra was recorded using Bruker AMX- 400 instrument in deuterated chloroform $\left(\mathrm{CDCl}_{3}\right)$ and the $\delta$ values for ${ }^{1} \mathrm{H}$ were referenced relative to the residual non-deuterated solvent signal. Solvents were evaporated by rotary evaporator (RV10 Basic, IKA, Germany). For vacuum liquid chromatography (VLC) and gel permeation chromatography columns were packed with Kieselgel 60H (mesh 70-230) and lipophilic Sephadex (LH-20), respectively. Thin layer chromatography (TLC) was performed on precoated (TLC Silica gel $\mathrm{F}_{254}$, VWR International, UK) plates using $1 \%$ vanillin $/ \mathrm{H}_{2} \mathrm{SO}_{4}$ spray reagent to visualize the spots. All other chemicals, solvents and reagents were of analytical grade.

The whole plants were collected from Avoynogor, Jessore in the month of March, 2013 and was identified by Mr. Sarder Nasir Uddin, Principal Scientific oOfficer, Bangladesh National Herbarium where a voucher specimen (DACB Accession number 39532) representing this collection has been deposited.

The air dried powdered material $(300 \mathrm{~g})$ was extracted in a Soxhlet apparatus with 1.5 litre of methanol. The whole extract was concentrated at $40^{\circ} \mathrm{C}$ with a rotary evaporator (yield $9.29 \%$ ). A portion of the crude methanolic extract $(300 \mathrm{mg}$ ) was subjected to gel permeation chromatography using lipophilic Sephadex (LH-20). A mixture of $n$-hexane, dichloromethane and methanol

*Author for correspondence: <rashidma@du.ac.bd>. 
$(2: 5: 1)$ was used as for elution. A total of 15 fractions $(3 \mathrm{ml}$ each) were collected and screened by TLC. Preparative thin layer chromatography (PTLC) of fraction-5 using $15 \%$ ethyl acetate in petroleum ether afforded compound $\mathbf{1}$ and 3 , with $\mathrm{R}_{\mathrm{f}}$ of 0.42 and 0.52 , respectively.

A portion of the crude methanolic extract $(2.15 \mathrm{~g})$ was subjected to vacuum liquid chromatography (VLC) over silica gel $60 \mathrm{H}$ (70-230 mesh). The column was eluted with petroleum ether, followed by mixtures of petroleum ether and ethyl acetate, then with ethyl acetate and finally with ethyl acetate and methanol mixtures of increasing polarities. A total of 19 fractions were collected and on the basis of TLC characteristics, the VLC fraction eluted with 3\% ethyl acetate in petroleum ether was further investigated. The spots in the developed TLC plates became purple upon spraying with $1 \%$ vanillin/ $\mathrm{H}_{2} \mathrm{SO}_{4}$ followed by heating at $110^{\circ} \mathrm{C}$ for $5-10$ min with $\mathrm{R}_{\mathrm{f}}$ 0.543 . This VLC fraction was subjected to PTLC over silica gel (Kieselgel $60 \mathrm{~F}_{254}$ ) using $7 \%$ ethyl acetate in petroleum ether to provide lupeol.

Stagmasterol (1): Colorless gum; ${ }^{1} \mathrm{H}$ NMR $\left(400 \mathrm{MHz}, \mathrm{CDCl}_{3}\right): \delta 0.68(3 \mathrm{H}, \mathrm{s}, \mathrm{Me}-13), 0.81$ and 0.84 (each $\left.3 \mathrm{H}, \mathrm{d}, J=7.2 \mathrm{~Hz}, \mathrm{Me}_{2}-25\right), 0.82(3 \mathrm{H}, \mathrm{m}, \mathrm{Me}-28), 0.92(3 \mathrm{H}, \mathrm{d}, J=6.8 \mathrm{~Hz}, \mathrm{Me}-20)$, $0.92(1 \mathrm{H}, \mathrm{m}, \mathrm{H}-20), 1.00(3 \mathrm{H}, \mathrm{s}, \mathrm{Me}-10), 3.52(1 \mathrm{H}, \mathrm{m}, \mathrm{H}-3), 5.02(1 \mathrm{H}, \mathrm{dd}, J=15.2,8.4 \mathrm{~Hz}, \mathrm{H}-$ 23), $5.12(1 \mathrm{H}, \mathrm{dd}, J=15.2,8.8 \mathrm{~Hz}, \mathrm{H}-22), 5.32(1 \mathrm{H}, \mathrm{m}, \mathrm{H}-6)$.

Lupeol (2): Colorless gum; ${ }^{1} \mathrm{H}$ NMR (400 MHz, $\left.\mathrm{CDCl}_{3}\right): \delta 0.74(3 \mathrm{H}, \mathrm{s}, \mathrm{Me}-24), 0.79(3 \mathrm{H}, \mathrm{s}$, Me -28), $0.84(3 \mathrm{H}, \mathrm{s}, \mathrm{Me}-25), 0.91(3 \mathrm{H}, \mathrm{s}, \mathrm{Me}-27), 0.95(3 \mathrm{H}, \mathrm{s}, \mathrm{Me}-23), 1.03(3 \mathrm{H}, \mathrm{s}, \mathrm{Me}-26)$, $1.66(3 \mathrm{H}, \mathrm{s}, \mathrm{Me}-30), 2.38(1 \mathrm{H}, \mathrm{m}, \mathrm{H}-19), 3.20(1 \mathrm{H}, \mathrm{dd}, J=11.0,5.0 \mathrm{~Hz}, \mathrm{H}-3), 4.52\left(1 \mathrm{H}, \mathrm{br} . \mathrm{s}, \mathrm{H}_{\mathrm{b}^{-}}\right.$ 29), 4.65 (1H, br. s, $\left.\mathrm{H}_{\mathrm{a}}-29\right)$.

Lup-20(29)-ene-3ß,23-diol (3): Colorless gum; ${ }^{1} \mathrm{H}$ NMR (400 MHz, $\left.\mathrm{CDCl}_{3}\right): \delta 0.67(1 \mathrm{H}$, br.d, $J=7.79 \mathrm{~Hz}, \mathrm{H}-5), 0.77$ (3H, s, Me-4), 0.81 (3H, s, Me-17), 0.92 (3H, s, Me-10), 0.95 (3H, s, Me8), $1.03(3 \mathrm{H}, \mathrm{s}, \mathrm{Me}-14), 1.23(1 \mathrm{H}, \mathrm{m}, \mathrm{H}-9), 1.29\left(2 \mathrm{H}, \mathrm{m}, \mathrm{H}_{2}-22\right), 1.34\left(2 \mathrm{H}, \mathrm{m}, \mathrm{H}_{2}-21\right), 1.39(2 \mathrm{H}$, $\left.\left.\mathrm{m}, \mathrm{H}_{2}-7\right), \delta 1.40\left(2 \mathrm{H}, \mathrm{m}, \mathrm{H}_{2}-11\right), 1.43\left(2 \mathrm{H}, \mathrm{m}, \mathrm{H}_{2}-15\right), 1.44\left(2 \mathrm{H}, \mathrm{m}, \mathrm{H}_{2}-12\right), 1.45,1 \mathrm{H}, \mathrm{m}, \mathrm{H}-18\right)$, $1.48\left(2 \mathrm{H}, \mathrm{m}, \mathrm{H}_{2}-16\right), 1.51\left(2 \mathrm{H}, \mathrm{m}, \mathrm{H}_{2}-6\right), 1.63\left(2 \mathrm{H}, \mathrm{m}, \mathrm{H}_{2}-1\right), 1.66(3 \mathrm{H}, \mathrm{s}, \mathrm{Me}-20), 1.68(1 \mathrm{H}, \mathrm{m}, \mathrm{H}-$ 13), $\delta 1.68\left(2 \mathrm{H}, \mathrm{m}, \mathrm{H}_{2}-2\right), 2.27(1 \mathrm{H}, \mathrm{ddd}, J=11.0,11.0,5.0 \mathrm{~Hz}, \mathrm{H}-19), 3.16(1 \mathrm{H}, \mathrm{dd}, J=9.2,4.0$ $\mathrm{Hz}, \mathrm{H}-3), 3.39$ (2H, br.s, $\left.\mathrm{H}_{2}-28\right), 4.54\left(1 \mathrm{H}\right.$, br.s, $\left.\mathrm{H}_{\mathrm{b}}-29\right), 4.66\left(1 \mathrm{H}\right.$, br.s, $\left.\mathrm{H}_{\mathrm{a}}-29\right)$.

A total of three compounds were isolated from methanol extract of the whole plants of $H$. schulli by repeated chromatographic separation and purification over lipophilic Sephadex LH-20 and silica gel. The structures of these compounds were elucidated as stigmasterol (1), lupeol (2) and lup-20(29)-ene-3ß,23-diol (3) on the basis ${ }^{1} \mathrm{H}$ NMR of spectral analysis and by comparing their ${ }^{1} \mathrm{H}$ NMR data with published values and also by co-TLC with authentic sample, whenever possible.

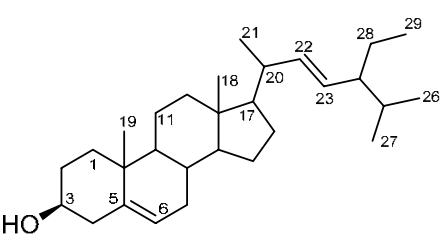

Stigmasterol

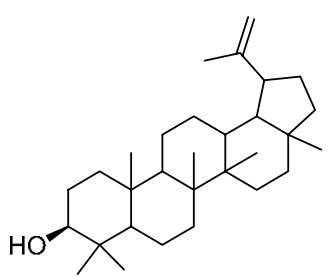

Lupeol

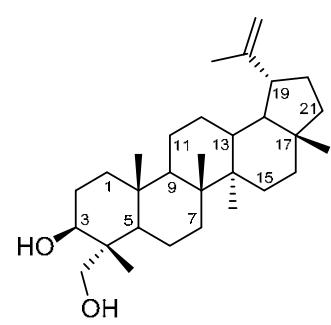

Lup-20(29)-ene-3ß,23-diol

Compound 1 was identified as stigmasterol by direct comparison of its ${ }^{1} \mathrm{H}$ NMR spectrum with that acquired for stigmasterol as well as by co-TLC (Haque et al. 2005, Chowdhury et al. 2008).

The ${ }^{1} \mathrm{H}$ NMR spectrum $\left(400 \mathrm{MHz}, \mathrm{CDCl}_{3}\right)$ of compound 2 showed a double doublet $(\mathrm{J}=$ $11.0,5.0 \mathrm{~Hz}$ ) of one proton intensity centered at $\delta 3.20$ typical for an oxymethine proton at C-3 of 
a triterpene skeleton. The splitting pattern and $\mathrm{J}$ values of this proton confirmed the $\beta$ (beta) orientation of the C-3 oxygenated substituent. The spectrum displayed two broad singlets at $\delta 4.65$ and $4.52(1 \mathrm{H}$ each) assignable to the vinylic protons at C-29. It also showed seven singlets for methyl protons at $\delta 0.95,0.74,1.03,0.84,0.91,0.79$ including a methyl on a vinylic moiety at $1.66\left(3 \mathrm{H}\right.$ each) assignable to the methyl group protons at $\mathrm{C}-4\left(\mathrm{H}_{3}-23, \mathrm{H}_{3}-24\right), \mathrm{C}-8\left(\mathrm{H}_{3}-26\right), \mathrm{C}-10$ $\left(\mathrm{H}_{3}-25\right), \mathrm{C}-14\left(\mathrm{H}_{3}-27\right), \mathrm{C}-17\left(\mathrm{H}_{3}-28\right)$ and $\mathrm{C}-20\left(\mathrm{H}_{3}-30\right)$, respectively. On this basis, compound 2 was characterized as lupeol. The identity of $\mathbf{2}$ was further confirmed by comparing its spectral data with previously reported values (Ferdous et al. 2010) as well as co-TLC with an authentic sample of lupeol, previously isolated in our laboratory.

The ${ }^{1} \mathrm{H}$ NMR spectrum of compound 3 displayed the two broad singlets at $\delta 4.66$ and 4.54 $\left(1 \mathrm{H}\right.$, each) which suggested the presence of vinylic protons at $\mathrm{H}_{2}-29$, while a three proton singlet at $\delta 1.66(\mathrm{Me}-30)$ indicated the presence of a isopropenyl side chain, characteristic of the lup20(29)-ene series of pentacyclic triterpenoid skeletons. On the other hand, the spectrum also showed five three proton singlets at $\delta 1.03,0.95,0.92,0.81$ and 0.77 assignable to the methyl groups at $\mathrm{C}-14\left(\mathrm{H}_{3}-27\right), \mathrm{C}-8\left(\mathrm{H}_{3}-26\right), \mathrm{C}-10\left(\mathrm{H}_{3}-25\right), \mathrm{C}-17\left(\mathrm{H}_{3}-28\right)$ and $\mathrm{C}-4\left(\mathrm{H}_{3}-24\right)$, respectively. The multiplet of one proton intensity at $\delta 2.27$ was attributed to $\mathrm{H}-19$. The ${ }^{1} \mathrm{H}$ NMR spectrum of 3 also displayed a broad multiplet of two proton intensity at $\delta 3.39$ which could be ascribed to the oxymethylene protons at $\mathrm{C}-23$. These ${ }^{1} \mathrm{H}$ NMR spectral features of compound $\mathbf{3}$ are almost identical to those published for lup-20(29)-ene-3 $\alpha, 23$-diol (Hui et al. 2009), except the comparatively upfield signal at $\delta 3.16(\mathrm{dd}, J=9.2,4.0 \mathrm{~Hz}$ ) which could be assigned to $\mathrm{H}-3$ in a pentacyclic triterpenoid type carbon skeleton. The splitting pattern and large coupling constant suggested that the C-3 hydroxyl substituent was at $\beta$-position. Therefore, $\mathrm{C}-3$ proton is in $\alpha$ orientation. Thus, the identity of compound $\mathbf{3}$ was established as lup-20(29)-ene-33,23-diol.

\section{References}

Ahmed ZU Hassan MA, Begum ZNT, Khondker M, Kabir SMH, Ahmad M, Ahmed ATA, Rahman AKA and Haque EU (Eds) 2007-2009. Encyclopedia of Flora and Fauna of Bangladesh. Angiosperms; Dicotyledons. Vols. 6-12. Asiatic Society of Bangladesh, Dhaka.

Ara K, Haque MR, Kaiser MA, Rahman AHMM, Hasan CM and Rashid MA 2012. A new diarylheptanoid from Garuga pinnata Roxb. Dhaka Univ. J. Pharm. Sci. 12: 165-167.

Begum F, Haque MR, Nahar KS and Rashid MA 2014. Secondary metabolites from different extractives of Stereospermum suaveolens. Dhaka Univ. J. Pharm. Sci. 13: 31-36.

Chowdhury SA, Sohrab MH, Haque MR, Hasan CM and Rashid MA 2008. Phytochemical and biological investigations of Polygonum lanatum. Orient. Pharm. Exp. Med. 8: 97-102.

Ferdous F, Hossain MK, Rahman MS, Hossain MA, Kabir S and Rashid MA 2010. Chemical and biological investigations of Samanea saman (Jacq.) Merr. Dhaka Univ. J. Pharm. Sci. 9: 69-73.

Haque ME, Shekhar HU, Mohamad A, RahmanH, Islam AKMM and Hossain MS 2006. Triterpenoids from the stem bark of Avicennia officinalis. Dhaka Univ. J. Pharm.

Sci. 5: 53-57.

Haque MR, Rahman KM, Begum B, Hasan CM and Rashid MA 2005. Secondary metabolites from Stereospermum chelonoides. Dhaka Univ. J. Pharm. Sci. 4: 61-64.

Haque MR, Rahman KM, Hasan CM and Rashid MA 2006. Antimicrobial and cytotoxic activities of Stereospermum chelonoides. Dhaka Univ. J. Pharm. Sci. 5: 71-72.

Hui (Miss) WH and Lee WK 1971. An examination of the Euphorbiaceae of Hong Kong. Part VIII. Lup20(29)-ene-3 $\alpha$,23-diol, a new triterpene from Glochidion macrophylhm Benth. J. Chem. Soc. C: 10041006.

Sikder AA, Sharmin T, Rahman AFMM, Hasan CM and Rashid MA 2013. Screenings of four medicinal plants of Bangladesh for bioactivities. Dhaka Univ. J. Pharm. Sci. 12: 59-62.

(Manuscript received on 28 December, 2014; revised on 5 April, 2015) 